\title{
Narrow Pore-Diameter Polypyrrole Nanotubes
}

\author{
Xinyu Zhang and Sanjeev K. Manohar* \\ Alan G. MacDiarmid Center for Innovation, Department of Chemistry, The University of Texas at Dallas, \\ Richardson, Texas 75080
}

Received July 17, 2005; E-mail: sanjeev.manohar@utdallas.edu

We describe the bulk synthesis of microns long electrically conducting polypyrrole nanotubes having $6 \mathrm{~nm}$ average pore diameter by chemical oxidative polymerization of pyrrole using $\mathrm{FeCl}_{3}$ oxidant and $\mathrm{V}_{2} \mathrm{O}_{5}$ nanofibers as the sacrificial template. These nanotubes undergo a spontaneous redox reaction with noble metal ions under mild aqueous conditions, resulting in deposition of 3-8 $\mathrm{nm}$ size particles of $\mathrm{Ag}, \mathrm{Au}, \mathrm{Pd}$, etc., on the tube surface. Metal nanoparticles rapidly migrate from the nanotube surface to the pore and, in the case of $\mathrm{Ag}$, coalesce in the core, yielding 4-8 nm diameter coaxial cables of $\mathrm{Ag}$ surrounded by a $20-30 \mathrm{~nm}$ thick polypyrrole fiber sheath, affording a facile entry into this technologically important class of metal-polymer nanocomposites.

In contrast to the myriad of synthetic approaches to nanofibers of conducting polymers, ${ }^{1}$ there are fewer reports on the synthesis of conducting polymer nanotubes. ${ }^{2}$ Soft (organic) template approaches include the use of large organic dopant anions and surfactant-based reverse microemulsion systems, ${ }^{3}$ while hard (inorganic) template approaches involve solution or vapor phase polymerization along the pore walls of anodic aluminum oxide, ${ }^{4}$ track-etched membranes, ${ }^{5}$ etc. Pore diameters in the $20-100 \mathrm{~nm}$ range have been synthesized using hard templates. ${ }^{3,4}$ To the best of our knowledge, there has not been a report of conducting polymer nanotubes having inner (pore) diameter less than $10 \mathrm{~nm}$. In this study, we report a simple and rapid method to chemically synthesize bulk quantities of 60-80 nm diameter (outer diameter) nanotubes of doped polypyrrole having pore diameter in the range of 4-8 $\mathrm{nm}$ using a variation of our recently reported "nanofiber seeding" method to synthesize nanofibers of polypyrrole $\left(\mathrm{V}_{2} \mathrm{O}_{5}\right.$-seeding). ${ }^{6}$ When used in larger amounts, $\mathrm{V}_{2} \mathrm{O}_{5}$ nanofibers do not act as seeds but as polymerization templates $\left(\mathrm{V}_{2} \mathrm{O}_{5}\right.$-templating), yielding nanotubes composed of a solid $\mathrm{V}_{2} \mathrm{O}_{5}$ pore surrounded by a polypyrrole sheath. The $\mathrm{V}_{2} \mathrm{O}_{5}$ in the pore dissolves readily in dilute aqueous acids during the product purification step, yielding hollow polypyrrole nanotubes.

Polypyrrole nanotubes were synthesized by $\mathrm{V}_{2} \mathrm{O}_{5}$-templating as follows. A mixture of ethanol $(50 \mathrm{~mL})$ and $10-15 \mathrm{~nm}$ diameter nanofibers of $\mathrm{V}_{2} \mathrm{O}_{5}$ sol-gel $(2.0 \mathrm{~mL})^{6}$ was magnetically stirred for $12 \mathrm{~h}$, and pyrrole monomer $(14.9 \mathrm{mmol})$ was added, followed by anhydrous $\mathrm{FeCl}_{3}$ oxidant $(10 \mathrm{mmol})$ to initiate the polymerization. The solution immediately turned dark brown, and after $1 \mathrm{~h}$, the black precipitate of polypyrrole nanotubes having $10-15 \mathrm{~nm}$ diameter $\mathrm{V}_{2} \mathrm{O}_{5}$ cores was suction filtered and suspended in aq. 1.0 $\mathrm{M} \mathrm{HCl}(100 \mathrm{~mL})$ for $2 \mathrm{~h}$ to leach out the $\mathrm{V}_{2} \mathrm{O}_{5}$ from the pore. Suction filtration followed by drying under dynamic vacuum at 80 ${ }^{\circ} \mathrm{C}$ for $12 \mathrm{~h}$ yielded $\sim 50 \mathrm{mg}$ of polypyrrole nanotubes having conductivity of $\sigma_{\mathrm{RT}} \sim 2 \mathrm{~S} / \mathrm{cm}$ (pressed pellet). The bulk precipitate is composed entirely of a nonwoven mesh of 2-4 $\mu \mathrm{m}$ long nanotubes of doped polypyrrole having $4-8 \mathrm{~nm}$ pore diameter and 60-80 nm outer diameter (Figure 1). The control experiment carried out in the absence of $\mathrm{V}_{2} \mathrm{O}_{5}$ yielded only granular polypyrrole $\cdot \mathrm{Cl}$, as shown in Supporting Information.

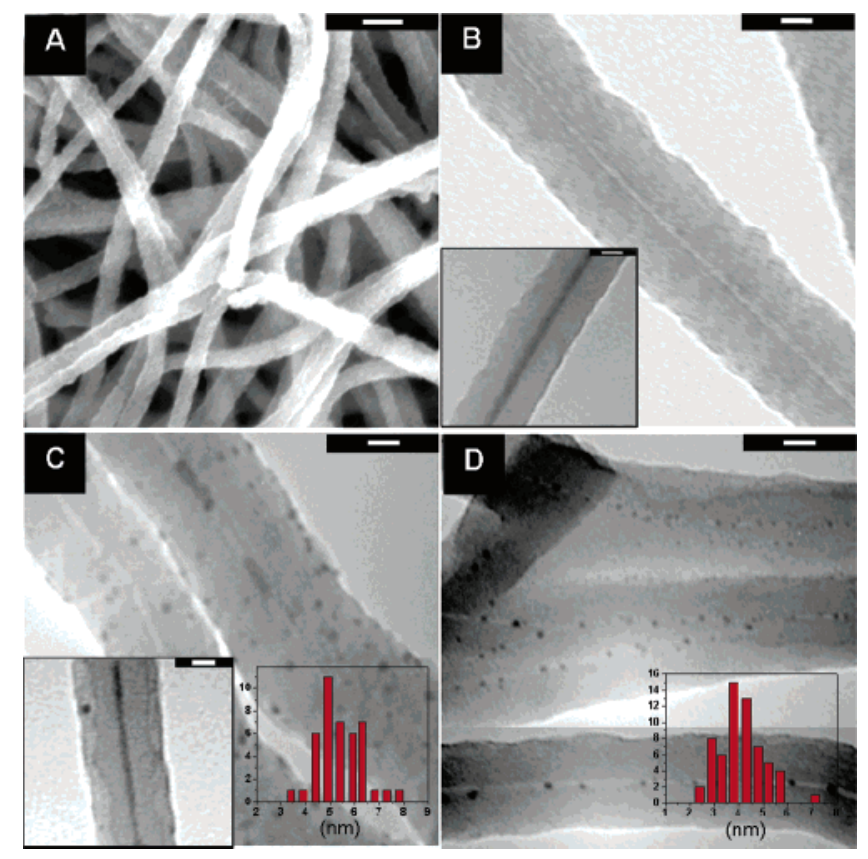

Figure 1. Polypyrrole $\cdot \mathrm{Cl}$ nanotubes: (A) SEM, as-synthesized. (B) TEM, as-synthesized showing hollow tube. Inset: TEM showing pore filled with $\mathrm{V}_{2} \mathrm{O}_{5}$. (C) TEM, Ag nanocomposite. Insets: coaxial cable of $\mathrm{Ag}$ and particle size distribution (D) TEM, Au nanocomposite. Inset: particle size distribution. Scale: (A) $100 \mathrm{~nm}$; (B, C, D) $20 \mathrm{~nm}$.

The elemental composition of the nanofibers by EDX is as follows: C, 62.38; N, 18.83; Cl, 15.39; O, 3.40; consistent with the structure $(\mathrm{PPy})(\mathrm{Cl})_{0.32}\left(\mathrm{H}_{2} \mathrm{O}\right)_{0.16}$ and similar to polypyrrole $\cdot \mathrm{Cl}$ nanofibers obtained in the $\mathrm{V}_{2} \mathrm{O}_{5}$-seeded polymerization of pyrrole in aq. 1.0 $\mathrm{M} \mathrm{HCl}{ }^{6}$ Vibrational spectra ( $\mathrm{KBr}$ pellet) and aqueous electrochemistry are also consistent with polypyrrole $\cdot \mathrm{Cl}$ nanofibers synthesized by $\mathrm{V}_{2} \mathrm{O}_{5}$-seeding. There are, however, significant differences in the synthetic method between the templating and seeding systems apart from the lower conductivity of nanotubes (2 $\mathrm{S} / \mathrm{cm})$ compared to that of nanofibers $(50 \mathrm{~S} / \mathrm{cm})$. While fibrillar polymer growth is favored under aqueous acidic conditions having seed quantities of $\mathrm{V}_{2} \mathrm{O}_{5}$ nanofibers, tubular polymer growth is favored under nonaqueous neutral conditions containing larger amounts of $\mathrm{V}_{2} \mathrm{O}_{5}$ nanofibers; for example, 2-3 times the amount of $\mathrm{V}_{2} \mathrm{O}_{5}$ nanofibers is used in $\mathrm{V}_{2} \mathrm{O}_{5}$-templating versus $\mathrm{V}_{2} \mathrm{O}_{5}$-seeding systems. The reaction yield is also significantly lower (e.g., $18 \%$ for nanotubes versus $95 \%$ for nanofibers). The combination of low reaction yield and high $\mathrm{V}_{2} \mathrm{O}_{5}$ amounts in the reaction mixture is consistent with $\mathrm{V}_{2} \mathrm{O}_{5}$ nanofibers acting as templates rather than seeds during the polymerization; that is, there are sufficient $\mathrm{V}_{2} \mathrm{O}_{5}$ nanofibers to constitute the core of the polypyrrole nanotubes that are formed. We believe that nanotube formation proceeds as follows: (i) adsorption and oxidative polymerization of pyrrole on the surface of the $\mathrm{V}_{2} \mathrm{O}_{5}$ nanofiber template, which constitutes the 
pores of the tube, and (ii) removal of the $\mathrm{V}_{2} \mathrm{O}_{5}$ template by aq. 1.0 $\mathrm{M} \mathrm{HCl}$ during the purification step. We have previously shown in the $\mathrm{V}_{2} \mathrm{O}_{5}$-seeded system that $\mathrm{V}_{2} \mathrm{O}_{5}$ nanofibers act as sacrificial seeds and dissolve readily in aq. $1.0 \mathrm{M} \mathrm{HCl}$ during the synthesis of polypyrrole nanofibers. ${ }^{6}$ Under neutral and largely nonaqueous conditions, however, the $\mathrm{V}_{2} \mathrm{O}_{5}$ nanofibers would remain in suspension and act as templates for polymerization, yielding, as the initial product, coaxial cables composed of $10-15 \mathrm{~nm}$ diameter $\mathrm{V}_{2} \mathrm{O}_{5}$ core encased in 60-80 nm diameter polypyrrole sheath (Figure 1B inset). Both TEM images and elemental analysis of this initial product (C, 56.06; N, 16.38; Cl, 11.96; O, 4.92; V, 4.51; Fe, 6.17) are consistent with this rationale. Upon "washing" with aq. $1.0 \mathrm{M} \mathrm{HCl}$, there is complete removal of both $\mathrm{V}$ and $\mathrm{Fe}\left(\mathrm{FeCl}_{4}{ }^{-}\right.$dopant replaced by $\mathrm{Cl}^{-}$), resulting in tubes with a pore diameter in the $4-8 \mathrm{~nm}$ range. It is important to note that, although the pore diameter gets smaller upon removal of $\mathrm{V}_{2} \mathrm{O}_{5}$, the tube does not collapse to yield a fiber, opening opportunities to "back-fill" the core with oxides, metals, etc.

As-synthesized doped polypyrrole nanotubes with hollow pores spontaneously reduce noble metal ions to the corresponding metal nanoparticles at room temperature without any capping or dispersing agents and are themselves oxidized in the process. ${ }^{7}$ For example, 3-5 nm nanoparticles of $\mathrm{Ag}, \mathrm{Au}$, and $\mathrm{Pd}$, etc., deposit readily on the surface of the tubes, which then migrate spontaneously to the pore. Metal ion reduction is extremely rapid in the $\mathrm{Ag}^{+} / \mathrm{Ag}$ system and is complete in less than $5 \mathrm{~min}$, while $\mathrm{Au}^{3+} / \mathrm{Au}$ system takes $\sim 1 \mathrm{~h}$. Narrow particle-size distributions are observed for both $\mathrm{Ag}$ and $\mathrm{Au}$ nanocomposites, that is, $3-8 \mathrm{~nm}$ range with an average of $5.4 \mathrm{~nm}$ for $\mathrm{Ag}$ and $2-7 \mathrm{~nm}$ range with an average of $4.1 \mathrm{~nm}$ for $\mathrm{Au}$ (Figure 1C,D). Ag nanoparticles also readily agglomerate in the pore, yielding 4-8 $\mathrm{nm}$ diameter Ag nanocables encased in a polypyrrole sheath (Figure 1C inset), and these nanocables are present alongside Ag nanoparticles on the tube surface and in the interior of the polypyrrole sheath. In contrast, Au nanoparticles are observed in the pore region (Figure 1D).

While there are a few recent reports on the synthesis and applications of metal/polyaniline nanocomposites, ${ }^{8}$ to our knowledge, the present study is the first use of doped conducting polypyrrole to chemically synthesize noble metal nanoparticles less than $5 \mathrm{~nm}$ in size under mild aqueous conditions. We believe significant opportunities exist at particle sizes below $10 \mathrm{~nm}$ when surface free energy contributions to the total free energy of the system become more important. In a recent study on the aqueous electrochemistry of 3-7 $\mathrm{nm}$ size monolayer-coated Ag nanoclusters, ${ }^{9}$ a correlation was observed between particle size and separation between anodic and cathodic peaks $\left(E_{\mathrm{ox}}-E_{\mathrm{red}}\right)$, although the high resistivity of the monolayer coating was responsible for small peak currents and considerable irreversibility in redox behavior. In contrast, Ag/polypyrrole composites display high currents and excellent reversibility that is most likely facilitated by the electrically conducting and redox active polypyrrole matrix (Figure 2). Compared to $\mathrm{Ag}$ wire (control), the redox peaks for the $\mathrm{Ag} /$ polypyrrole composite are more symmetric with a significantly smaller $E_{\mathrm{ox}}-E_{\text {red }}$ value consistent with small Ag particle size (400 versus $600 \mathrm{mV}) .{ }^{9}$ Redox equilibrium is established quickly in the composite with very little drift in the redox peak positions from the initial scan. The magnitude of $E_{\mathrm{ox}}-E_{\mathrm{red}}$ as a function of scan rate is also similar for the two systems, indicating rapid electron transfer despite a semiconducting polypyrrole matrix (Figure 2

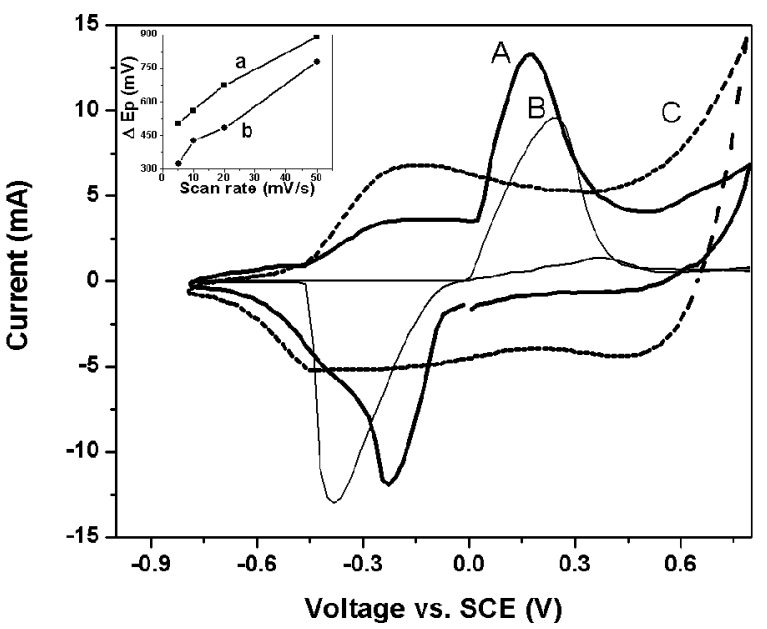

Figure 2. Cyclic voltammetry of (A) Ag/polypyrrole nanotube composite; (B) $\mathrm{Ag}$ wire. (C) As-synthesized polypyrrole nanotubes (aq. $1.0 \mathrm{M} \mathrm{NaCl}$ electrolyte, $20 \mathrm{mV} / \mathrm{s}$, SCE reference). Inset: Scan rate dependence of (a) Ag wire; (b) Ag/polypyrrole nanotube composite.

inset). In this regard, it is to be noted that the conductivity of the $\mathrm{Ag} /$ polypyrrole composite $\left(10^{-2} \mathrm{~S} / \mathrm{cm}\right)$ is lower than that of assynthesized polypyrrole nanotubes $(2 \mathrm{~S} / \mathrm{cm})$, presumably as a result of oxidation of the polypyrrole backbone (over-oxidation) during redox reaction with noble metal ions (see Supporting Information).

In summary, the rapid, one-step reaction of the as-synthesized polypyrrole nanotubes with metal ions to yield highly electroactive nanoparticles coupled with the equally facile synthesis of small pore diameter polypyrrole nanotubes could open new opportunities in a myriad of applications, such as energy storage systems, catalysis, fuel cell membranes, nanoelectronics devices, and antibacterial coatings. The method is general and can be extended to other conducting polymers, such as polythiophene and PEDOT nanotubes.

Acknowledgment. We gratefully acknowledge helpful discussions with Dr. Alan G. MacDiarmid, and The University of Texas at Dallas for financial support.

Supporting Information Available: SEM, TEM, FTIR of polypyrrole and composites. This material is available free of charge via the Internet at http://pubs.acs.org.

\section{References}

(1) (a) Huang, J.; Kaner, R. B. J. Am. Chem. Soc. 2004, 126, 851. (b) Wang, Y.; Liu, Z.; Han, B.; Sun, Z.; Huang, Y.; Yang, G. Langmuir 2005, 21 833. (c) Zhang, X.; Goux, W. J.; Manohar, S. K. J. Am. Chem. Soc. 2004 126, 4502. (d) Zhang, X.; Manohar, S. K. Chem. Commun. 2004, 20 , 2360 .

(2) Wan, M. Encycl. Nanosci. Nanotechnol. 2004, 2, 153.

(3) (a) Jang, J.; Yoon, H. Chem. Commun. 2003, 720. (b) Zhang, L.; Wan, M. Thin Solid Films 2005, 477, 24.

(4) Jang, J.; Oh, J. H. Chem. Commun 2004, 882.

(5) Park, J. G.; Lee, S. H.; Kim, B.; Park, Y. W. Appl. Phys. Lett. 2002, 81 4625 .

(6) Zhang, X.; Manohar, S. K. J. Am. Chem. Soc. 2004, 126, 12714.

(7) Noble metal nanocomposites, including coaxial Ag cables, were synthesized by placing as-synthesized polypyrrole nanotubes $(10 \mathrm{mg})$ in aq. 0.01 $\mathrm{M} \mathrm{AgNO}_{3}$ (or $\mathrm{HAuCl}_{4}, \mathrm{PdCl}_{2}$ ) solution $(10 \mathrm{~mL}$ ) at room temperature for times ranging from 3 min for $\mathrm{AgNO}_{3}$ to $1 \mathrm{~h}$ for $\mathrm{HAuCl}_{4}$.

(8) (a) Huang, J.; Virji, S.; Weiller, B. H.; Kaner, R. B. Chem.-Eur. J. 2004, 10, 1314. (b) Smith, J. A.; Josowicz, M.; Janata, J. J. Electrochem. Soc 2003, 150, E384. (c) Tseng, R. J.; Huang, J.; Ouyang, J.; Kaner, R. B.; Yang, Y. Nano Lett. 2005, 5, 1077.

(9) Chaki, N. K.; Sharma, J.; Mandle, A. B.; Mulla, I. S.; Pasricha, R.; Vijayamohanan, K. Phys. Chem. Chem. Phys. 2004, 6, 1304.

JA054789V 